\title{
Nightmare in schizophrenic and depressed patients
}

Celestine Okorome Mume, BSc, MBChB, MSc, FMCPsych

Department of Mental Health, Faculty of

Clinical Sciences, Obafemi Awolowo

University, Ile - Ife, Osun State

NIGERIA

\begin{abstract}
Background and Objectives: Nightmare is a common sleep disorder. While a sleep disorder such as insomnia can readily be associated with psychiatric disorders, the same cannot be said of nightmare. The objective of this study was to determine the prevalence rate of nightmare in a sample of psychiatric patients, and to compare this rate with the rate obtained in age- and sex- matched healthy control subjects in order to determine if there is a significant difference in the rates of nightmare in the different groups.

Methods: Ninety - four randomly selected psychiatric patients made up of 54 schizophrenic patients and 40 depressed patients were recruited into the study. One hundred and twenty - three age- and sex- matched randomly selected control subjects were also recruited into the study. A questionnaire determining the one year prevalence of nightmare was administered to all the subjects. Each of them was required to indicate whether he or she had experienced nightmare in the previous one year and if so to indicate the number of episodes experienced during the said period.

Results: The results showed prevalent rates of nightmare of $4.9 \%, 16.7 \%$ and $17.5 \%$ respectively for the healthy control subjects, schizophrenic patients and depressed patients. There was an overall prevalence rate of $17 \%$ among the psychiatric patients (schizophrenic patients and depressed patients) as against $4.9 \%$ in the healthy control subjects. Among those who experienced nightmare, the mean values for the number of episodes within the previous one year were, respectively $18(\mathrm{sd}=6.6)$ for healthy control subjects $(n=6), 42.7(s d=6.3)$ for schizophrenic patients $(n=9)$ and $44.6(s d=5.9)$ for depressed patients $(\mathrm{n}=7)$.

Conclusions: The findings in this study provide support for a significant association between nightmare and schizophrenia as well as nightmare and depressive illness. In effect, there is a significant association between nightmare and psychopathology.
\end{abstract}

Received 19 March 2009

Revised 30 May 2009

Accepted 9 June 2009 


\section{Introduction}

Sleep is a physiological state characterized by a gross reduction in the individual's awareness and responsiveness to his environment. It is readily reversible with diurnal timing and duration ${ }^{1}$. The average adult human sleeps for about eight hours each day ${ }^{1}$. There are many other individuals who sleep for much less and much more hours each day.

The two main phases of sleep are nonrapid eye movement (NREM) sleep ${ }^{2}$, also called orthodox sleep or slow wave sleep $(\mathrm{SWS})^{3}$ and the rapid eye movement (REM) sleep also called paradoxical sleep. NREM sleep is further divided into four sleep stages on the basis of the electroencephalogram (EEG) : these are stages 1 through 4.

Ascending reticular activating system (ARAS) is very important for the generation and maintenance of waking states or arousal ${ }^{2}$. Sleep is a reflection of reduced activity of the ascending reticular activating system (ARAS). Contrasted with coma, mental activities continue to occur during sleep.

A dream is the recall of mental activity that has occurred during sleep ${ }^{4}$. A nightmare is a vivid and terrifying dream episode in which the dreamer is suddenly awakened from sleep. Typically, the dreamer wakes from REM sleep and is able to describe a detailed dream. Usually, the dreamer has difficulty returning to sleep.

Nightmares can lead to a negative conditioning toward sleep and to chronic sleep complaints $^{5}$.

Studies of the general population reveal that 5 to 8 percent of the adult population report a current problem with nightmares ${ }^{4}$. Nightmares are common in the population and may not necessarily be associated with underlying psychopathology especially in most children and in some adults. In some other situations however, nightmares are associated with increased stress and psychopathology.

Recurrent nightmares are the hallmark of post-traumatic stress disorder and may be associated with other psychiatric illnesses ${ }^{6}$. Nightmares are a defining symptom in posttraumatic stress disorder (PTSD) ${ }^{7,8}$. The occurrence of PTSD following trauma varies. Thirty percent of veterans of the Vietnam War were affected by PTSD, as were 68 percent of veterans who were in the Arab-Israeli conflict of 1973 and 8 percent of veterans of the Gulf War ${ }^{4,9}$.

Nightmares can occur in patients with psychiatric illness. Depression is sometimes associated with themes of poor self-image in dreams ${ }^{10}$. Schizophrenic patients may have frightening dreams during a relapse of the illness. The REM sleep rebound related to withdrawal from alcohol and sedativehypnotics, which suppress REM sleep, may present as nightmares ${ }^{4,11}$.

Nightmare, like many other sleep disorders, is very prevalent in the general population and are associated with significant medical, psychological, and social disturbances. Nightmares are highly prevalent and should receive specific attention ${ }^{12}$.

The present study was designed to highlight nightmare as it occurs in healthy individuals and at the same time to demonstrate its possible association with psychopathology, using schizophrenia and depressive episode as examples of psychopathological states.

\section{Materials and Methods}

The study was carried out in the Psychiatric Outpatient Clinic of Obafemi Awolowo University Teaching Hospitals Complex 
(OAUTHC), Ile-Ife in South Western Nigeria. An approval by the local Ethical Committee, which is the Ethics and Research Committee of the Obafemi Awolowo University Teaching Hospitals Complex was obtained to carry this study.

The subjects who participated gave written informed consent after the study and its objectives had been explained to them. Ninety - four psychiatric patients made up of 54 schizophrenic patients and 40 depressed patients were recruited into the study. They were randomly selected from a group of patients attending the Psychiatric Outpatient clinic of the OAUTHC. One hundred and twenty - three age- and sexmatched randomly selected control subjects were also recruited into the study.

The group of healthy control subjects was drawn from the population of Ile - Ife, a city in Osun state in South Western Nigeria. A questionnaire determining the one year prevalence of nightmare was administered to all the subjects. Each of them was required to indicate whether he or she had experienced nightmare in the previous one year and if so to indicate the number of episodes experienced during the said period.

The part of the questionnaire that was used to elicit information on nightmare is reproduced here: This questionnaire aims at obtaining information about nightmare which is one of the sleep disorders. A nightmare is a vivid and terrifying dream episode in which the dreamer is suddenly awakened from sleep. Typically, the dreamer wakes from sleep and is able to describe a detailed dream. Usually, the dreamer has difficulty returning to sleep. Did you experience nightmare in the past one year? Yes No

If yes, how many times did you experience it in the past one year?
This may be calculated based on the number of episodes of nightmare per month if it is difficult to remember the number of episodes per year. Individuals who had similar experiences in the daytime are not eligible for this study.

The data were analysed statistically to obtain the socio-demographic characteristics of the subjects in the different groups; the number and percentages of those who experienced nightmare in the different groups and the number of nightmare episodes were obtained in the different groups. Comparisons were done using Chi - square and by analysis of variance (ANOVA) (SAS Institute, Cary, NC) and Post hoc test (StudentNewman-Keuls) was carried out (following ANOVA) to determine the source of a significant effect, with $\mathrm{p}<0.05$.

\section{Results}

The age range for the healthy control subjects $(\mathrm{n}=123)$ was $18-53$ years, with a mean age of 42.6 years $(\mathrm{sd}=28.8)$; for the schizophrenic patients $(\mathrm{n}=54)$ it was 18 51 years with a mean age of 43.1 years $(\mathrm{sd}=$ 22.8) and for the patients with depressive episode $(n=40)$ the age range was $22-52$ years, with a mean age of 40.8 years $(\mathrm{sd}=$ 13.3). There was no significant difference in this distribution, $\mathrm{F}(2,214)=0.11, \mathrm{p}=0.900$. The full socio - demographic characteristics of the subjects are shown in Table I.

Nine (9) out of the 54 schizophrenic patients $(16.7 \%), 7$ out of the 40 depressed patients $(17.5 \%)$ and 6 out of the 123 healthy subjects $(4.9 \%)$ experienced nightmare in the previous one year. These are shown in Figure 1. Figure 2 shows that when put together, 6 out of the 123 healthy subjects and 16 out of 
Table I

Socio-demographic characteristic of the subjects in the study

\begin{tabular}{lccc} 
S/N Variable & $\begin{array}{c}\text { Healthy } \\
\text { Subjects }\end{array}$ & $\begin{array}{c}\text { Schizophrenic } \\
\text { patients }\end{array}$ & $\begin{array}{c}\text { Depressed } \\
\text { Patients }\end{array}$ \\
\hline $\begin{array}{l}\text { 1. Age range } \\
\quad \text { years) }\end{array}$ & $18-53$ & $18-51$ & $22-52$ \\
2. Sex & & & \\
$\quad$ Male & 73 & 35 & 19 \\
Female & 50 & 19 & 21 \\
3. Marital status & & & 13 \\
$\quad$ Single & 38 & 32 & 18 \\
Married & 79 & 11 & 5 \\
Separated & 6 & 10 & 0 \\
Divorced & 0 & 1 & 4 \\
$\quad$ Widowed & 0 & 0 & \\
\hline
\end{tabular}

\section{Subjects' Report of Nightmare}

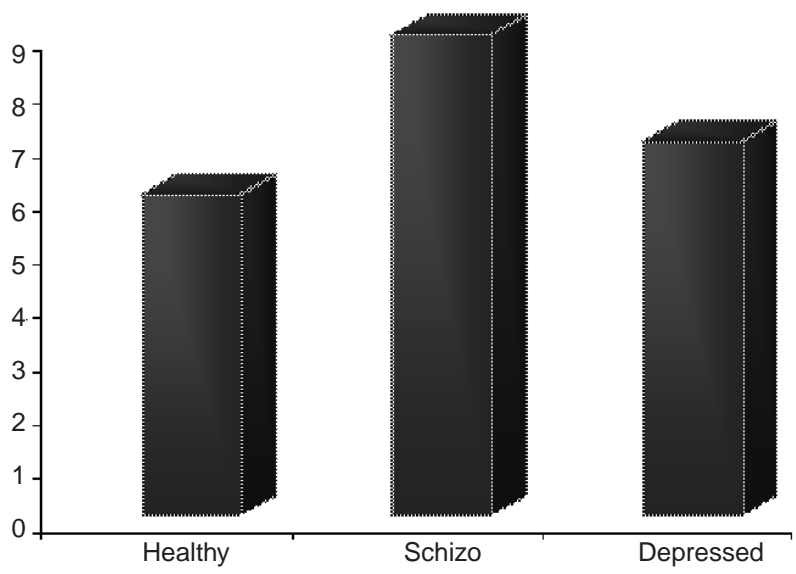

Figure 1. Subjects' report of nightmare. Six members of the healthy, control group (Healthy), nine of the schizophrenic patients (Schizo) and seven of the depressed patients (Depressed), experienced nightmare during the previous one year.

the 94 patients $(17 \%)$ experienced nightmare. Thus, nightmare was significantly $\left(\chi^{2}=7.343\right.$, df $=1, \mathrm{p}=0.007$ ) commoner among the psychiatric patients than in the control group. On the other hand there was no significant difference in the prevalence of nightmare between the schizophrenic group and the depressed patients $\left(\chi^{2}=0.029, \mathrm{df}=1, \mathrm{p}=0.864\right)$.

Considering the number of episodes of nightmare per year in those who experienced it, the mean values are respectively $18(\mathrm{sd}=$ 6.6) for healthy control subjects $(n=6), 42.7$ $(\mathrm{sd}=6.3)$ for schizophrenic patients $(\mathrm{n}=9)$ and $44.6(\mathrm{sd}=5.9)$ for depressed patients $(\mathrm{n}$ $=7$ ). Analysis of variance (ANOVA) showed that nightmare was significantly commoner in both the schizophrenic and the depressed patients compared to the healthy control subjects $[\mathrm{F}(2,19)=36.72, \mathrm{p}<0.05]$. This is illustrated in Figure 3. 


\section{Subjects' Report of Nightmare (All patients together)}

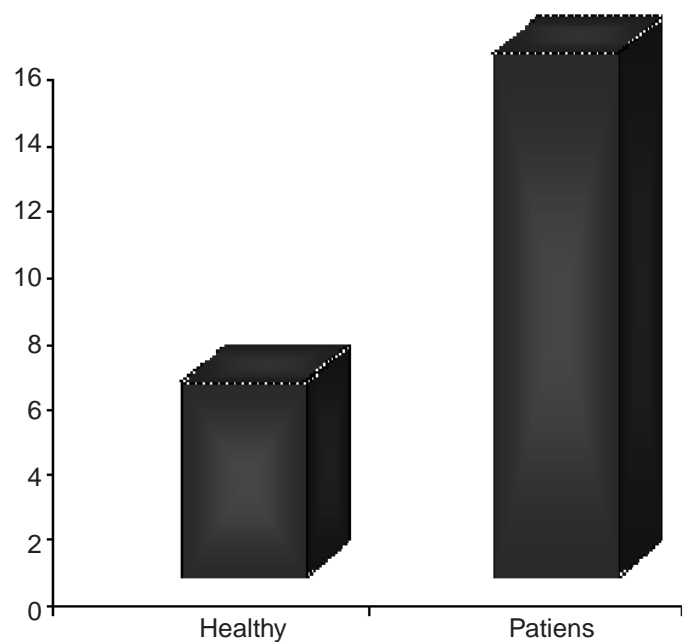

Figure 2. Subjects' report of nightmare. Six members of the healthy, control group (Healthy) $(n=123)$ and 16 psychiatric patients (Patients) $(\mathrm{n}=94)$ experienced nightmare during the previous one year. Nightmare was significantly $\left(\chi^{2}=7.343, \mathrm{df}=1, \mathrm{p}=0.007\right)$ commoner among the psychiatric patients than in the control group.

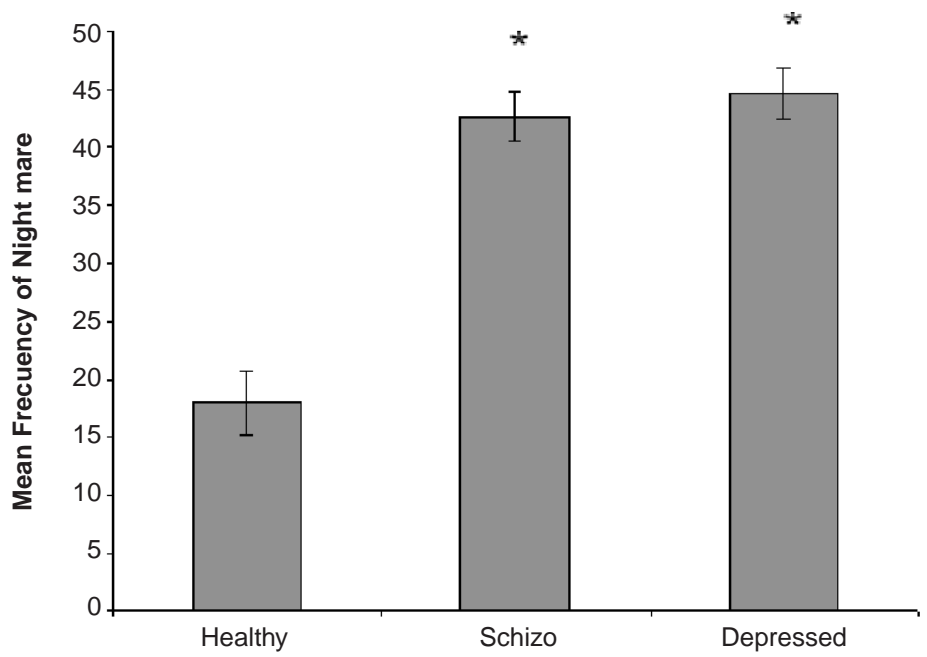

Figure 3. The number of episodes of nightmare per year in the healthy, control subjects (Healthy), the schizophrenic patients (Schizo) and the depressed patients (Depressed). Values are expressed as mean \pm SEM, *p $<0.05$ vs the healthy, control subjects (Healthy). 


\section{Discussion}

A nightmare is an extremely frightening dream from which the individual wakes up with vivid memory of the dream. The prevalence of nightmare in the healthy control subjects in this study is $4.9 \%$. This figure approximates that reported in some of the previous studies in which $5 \%$ to $8 \%$ of adults in the general population report a current problem with nightmares ${ }^{2}$.

Nightmares are have also been reported to be occurring weekly in $4 \%-10 \%$ of the population, and to be associated with increased stress and psychopathology ${ }^{6}$.

Borderline personality disorder patients have been reported to suffer a significantly greater rate of nightmares than control subjects do. Furthermore, borderline patients who suffered from nightmare disorder exhibited greater psychopathology as compared to those without nightmare disorder ${ }^{13}$. It was also found that lifelong nightmare sufferers had significantly higher scores on the "psychotic" side of the Minnesota Multiphasic Personality Inventory profile and scored higher on a "boundary deficit" score of the Rorschach test when compared with non - sufferers ${ }^{14}$.

It has been argued that nightmares are more than a symptom of a another syndrome such as anxiety disorder and should be viewed as a separate sleep disorder that should receive specific treatment ${ }^{12}$.

The prevalence of nightmare in the psychiatric patients in this study is high. The findings of this study provide support for an association between nightmare and schizophrenia as well as nightmare and depressive illness. While the association between nightmare and posttraumatic stress disorder has been recognized for a long time, little seems to be realized about similar association between nightmare and other pathological states.

Conclusion: The findings of this study provide support for an association between nightmare and schizophrenia as well as nightmare and depressive illness, thus effectively providing empirical support for a significant association between nightmare and psychopathological states other than posttraumatic stress disorder.

\section{References}

1. Roth T, Roehrs T. An overview of normal sleep and sleep disorders. Eur J Neurol 2000; (suppl 4): 3-8.

2. Gillin JC, Seifritz E, Zoltoski R, Salin-Pascual RJ. Basic Science of Sleep. In: Kaplan \& Sadock's, eds. Comprehensive Textbook of Psychiatry, Seventh Edition. Philadelphia: Lippincott Williams \& Wilkins; 2000. p. 3441-3667.

3. Dement WC. The occurrence of low voltage fast encephalogram patterns during behavioural sleep in the cat. Electroencephalogr Clin Neurophysiol 1958; 10: 291-296.

4. Pagel JF. Nightmares and disorders of dreaming. Am Fam Physician 2000; 61(7): 2037-2042.

5. Ohayon MM, Morselli PL, Guilleminault C. Prevalence of nightmares and their relationship to psychopathology and daytime functioning in insomnia subjects. Sleep 1997; 20(5): 340-348.

6. Nielsen TA. Disturbed dreaming, posttraumatic stress disorder, and affect distress: a review and neurocognitive model. Psychol Bull 2007; 133 (3): 482-528.

7. Ross RJ, Ball WA, Sullivan KA, Caroff SN. Sleep disturbance as the hallmark of posttraumatic stress disorder. Am J Psychiatry 1989; 146: 697-707.

8. Fawzi MC, Pham T, Lin L, Nguyen TV, Ngo D, Murphy E, et al. The validity of posttraumatic stress disorder among Vietnamese refugees. J Trauma Stress 1997; 10: 101-108.

9. Yehuda R, McFarlane AC. Conflict between current knowledge about posttraumatic stress disorder and its original conceptual basis. Am J Psychiatry 1995; 152: 1705-1713. 
10. Beauchemin KM, Hays P. Dreaming away depression: the role of REM sleep and dreaming in affective disorders. J Affect Disord 1996; 41: 125-133.

11. The international classification of sleep disorders, revised: diagnostic and coding manual. Rochester, Minn.: American Sleep Disorders Association; 2001.

12. Spoormaker VI, Schredl M, van den Bout J. Nightmares: from anxiety symptom to sleep disorder. Sleep Med Rev 2006; 10 (1): 19-31.

13. Semiz UB, Basoglu C, Ebrinc S, Cetin M. Nightmare disorder, dream anxiety, and subjective sleep quality in patients with borderline personality disorder Psychiatry Clin Neurosci 2008; 62 (1): 48-55.
14. Hartmann E, Russ D, Oldfield M, Sivan I, Cooper S. Who has nightmares? The personality of the lifelong nightmare sufferer. Arch Gen Psychiatry 1987; 44(1): 49-56.

Address for correspondence:

Dr Celestine O Mume

Department of Mental Health

Faculty of Clinical Sciences

Obafemi Awolowo University

Ile - Ife

Osun State

Nigeria

E-mail: celemume2000@yahoo.com 